\title{
Sustained Release Antiparkinson Agents: Controlled Release Levodopa
}

\author{
Serge Gauthier and Donna Amyot
}

\begin{abstract}
The rationale for sustained release oral levodopa preparations is to deliver levodopa in the areas of maximal intestinal absorption in a slow and predictable way, leading to stable plasma levodopa levels and brain dopamine levels, therefore resulting in a lengthened duration of action. Sinemet CR is the prototype of such preparations, with demonstrated efficacy in decreasing periods of akinesia in parkinsonian patients with mild to moderate motor fluctuations. Total doses of levodopa are raised 10 to $30 \%$ because of the lowered bioavailability; diphasic dyskinesias may increase at the end of the day. Tolerance is good in de novo patients and studies are in progress to establish if early treatment with Sinemet CR delays the onset or attenuates the severity of motor fluctuations as compared to standard Sinemet.

RÉSUMÉ: Agents antiparkinsoniens à libération prolongée: lévodopa à libération contrôlée. La justification de l'emploi de préparations orales de lévodopa à libération prolongée est de livrer la lévodopa dans les zones où l'absorption intestinale est maximale d'une façon lente et prévisible, produisant des taux plasmatiques de lévodopa et des taux cérébraux de dopamine qui sont stables, et conséquemment une durée d'action prolongée. Le Sinemet CR est le prototype de ce genre de préparations, son efficacité pour diminuer les périodes d'akinésie chez les parkinsoniens avec des fluctuations motrices de légères à modérées étant bien démontrée. Les doses totales de lévodopa sont augmentées de 10 à $30 \%$ à cause de la biodisponibilité réduite; les dyskinésies diphasiques peuvent augmenter en fin de journée. La tolérance est bonne lorsque le médicament est donné de novo et des études sont en cours pour établir si un traitement précoce avec le Sinemet CR retarde le début ou atténue la sévérité des fluctuations motrices par rapport au Sinemet standard.
\end{abstract}

Can. J. Neurol. Sci. 1992; 19: 153-155

The value and limitations of levodopa for the symptomatic therapy of Parkinson's disease (PD) are now well known. Predictable (wearing off) and unpredictable ("on/off") therapeutic response fluctuations have been linked to changes in levodopa plasma levels, dopamine (DA) brain levels and striatal DA receptors sensitivity. ${ }^{1,2}$ Physiologic limitations inherent to levodopa as an amino-acid include its (1) absorption over a relatively short segment of the proximal small intestine; (2) short plasma elimination half-life; (3) wide distribution in body tissues including muscles; (4) competition for transport through the intestinal mucosa and the blood-brain barrier with other large neutral amino-acids as well as its own principal metabolite, 3-0-methyldopa. ${ }^{3}$

One way to lessen the range of variation of levodopa plasma levels has been to combine oral levodopa with peripheral decarboxylase inhibitors (PDI) such as carbidopa (Sinemet) and benserazide (Madopar or Prolopa). Sinemet more than doubles levodopa plasma half-life as compared to levodopa administered without carbidopa. ${ }^{4}$ Another approach has been to modify oral levodopa/PDI tablets or capsules in order to obtain a sustainedrelease effect which may help (1) reduce existing therapeutic response fluctuations in PD patients already on levodopa and (2) prevent or delay the appearance of such fluctuations in de novo patients (not yet treated with levodopa). Brocadopa Temtabs, 5 Medidopa Retard, ${ }^{6}$ Madopar $\mathrm{HBS}^{7}$ and Sinemel CR4 ${ }^{8}$ have all been tested. Only the latter, made of a polymeric erodible matrix, is marketed in Canada and the U.S.A. under the trade name of Sinemet CR. It will thus be considered as the prototype of levodopa controlled release preparations (CRP) for the purpose of this review.

Current major sources of reference of this topic are the review on CRP by J.M. Cedarbaum ${ }^{3}$ and the symposium on Sinemet CR chaired by R.C. Duvoisin. ${ }^{9}$

\section{Pharmacokinetic Features}

The pharmacokinetic profile of Sinemet CR has been determined in healthy young and elderly volunteers, as well as in patients with $\mathrm{PD}$, using oral or intravenous routes, with or without food. $3,4.10 .11$

The published pharmacokinetic features of Sinemet CR compared to regular Sinemet have been summarized in Table 1. The $70 \%$ bioavailability secondary to the slower absorption process does result in a need for higher total daily doses of levodopa 10 obtain equivalent blood levels, but these levels are more stable.

From the McGill Centre for Studies in Aging, Montreal

Reprint requests to: Dr. S. Gauthier, McGill Centre for Studies in Aging, 1650 Cedar Avenue, Montreal, Quebec, Canada H3G 1A4 
The delayed $T_{\max }$ or time to initial peak is clinically significant: patients do complain of the loss of the "kick in" or "Popeye effect" that they may be dependent upon to start their day.

\section{Clinical Studies}

Efficacy and toxicity studies with Sinemet CR have involved PD patients with or without motor fluctuations, for periods up to two years. Most studies have been open substitution for regular Sinemet to Sinemet $\mathrm{CR}^{8.12 .19}$ and some studies have been double-blind cross-over in design (regular Sinemet to Sinemet CR or vice-versa). ${ }^{10,20,21}$

The pharmacokinetic properties of Sinemet CR lead logically to the clinical observations outlined in Table 2 . This overall gain in hours of mobility may be associated with an increase in dyskinesias at the end of the day, because of a progressive rise in plasma levels of levodopa. The potential use of Sinemet CR at bedtime has proven to be relatively disappointing, at least by one author ${ }^{3}$ who found that CR3 (which will not be marketed) and Madopar HBS (not marketed in Canada or the U.S.A.) would be more effective at night than Sinemet $C R$.

In open substitution studies, ${ }^{8.12-19}$ the overall results indicated that Sinemet CR improved mean efficacy scores in PD patients with mild to moderate motor fluctuations. Double-blind crossover studies have shown various results, ranging from no statis-

Table 1: Pharmacokinetic Features of Levodopa in Sinemet CR Relative to Regular Sinemet
AUC (area under the curve) for L-Dopa

AUC per mg dose of levodopa

Bioavailability

C max (initial peak levodopa concentration)

$\mathrm{C}$ min (plasma concentration at end of dose)

Dose equivalence of levodopa per day

$\mathrm{T}_{\max }$ (time to initial peak) increased

decreased

decreased +

decreased

increased

increased* increased
+ by as much as $30 \%$; increased by food, breaking tablet in half or chewing it

* by 20 to $30 \%$

Table 2: Clinical Features of Sinemet CR Relative to Regular Sinemet

$\begin{array}{ll}\text { Daily "off" periods } & \begin{array}{l}\text { decreased } \\ \text { decreased } \\ \text { Dosing frequency }\end{array} \\ \text { Duration of action } & \text { increased } \\ \text { Interdose interval } & \text { increased+ } \\ \text { Latency of action } & \text { not much change* } \\ \text { Morning akinesia } & \text { not much change* } \\ \text { Nocturnal mobility } & \text { increased" } \\ \text { Total daily dose of levodopa } & \text { decreased } \\ \% \text { "off" time } & \text { increased } \\ \% \text { "on" time without dyskinesias } & \text { increased" } \\ \text { \% "on" time with dyskinesias } & \end{array}$

+ may require one dose of regular Sinemet in the morning

* CR3 and Madopar HBS would have superior kinetic profiles than CR at night

- by 20 to $30 \%$

- especially diphasic dyskinesias
Table 3: Conversion from Regular Levodopa/DCI to Sinemet CR

Stop regular levodopa/DCI for 8 hours (overnight)

Add 10 to $30 \%$ more levodopa per day with dose intervals of at least 4 hours, smaller doses at the end of the day

$300-400 \mathrm{mg}$
$500-600 \mathrm{mg}$
$700-800 \mathrm{mg}$
$900-1000 \mathrm{mg}$

\section{Regular Levodopa/DCI}

Sinemet CR (200/50)

T bid

$\mathrm{T}$ bid or $\mathrm{T}^{\mathrm{l}} / 2$ bid

$\mathrm{T}^{1} / 2$ bid and $\mathrm{T}$ qd

2 bid and $T$ qd
Take with food during the day to increase bioavailability

tically significant differences in efficacy between regular Sinemet and Sinemet $\mathrm{CR}^{20}$ to small but statistically significant differences ${ }^{10}$ or modest differences. ${ }^{21}$ At best, a reduction of "off time" in the order of 40 minutes per day was found with the same side-effect profile as regular Sinemet. Motor fluctuations were not completely suppressed and dyskinesias, particularly of the diphasic type, were augmented in some patients.

Finally, a five year multicentre double-blind parallel (regular Sinemet or Sinemet CR) study with 500 de novo PD patients was initiated in 1989 by Bush et al. An interim analysis will be made two years into the study.

\section{Guidelines for Use of Sinemet CR}

The published data on Sinemet CR as the prototype of levodopa CRP suggest that it is a useful addition to existing symptomatic antiparkinsonian medications, although it does not replace the traditional considerations of (1) treating when symptoms are severe enough to interfere with functional autonomy at home or at work; (2) choosing the appropriate drug for the target symptoms, such as anticholinergics for tremor at rest and levodopa/DCI for akinesia and rigidity; (3) adding a direct DA agonist when four or more levodopa/DCI doses a day do not adequately control motor symptoms. When direct DA agonists (bromocriptine, pergolide) are not well tolerated or do not achieve adequate control of therapeutic response fluctuations, Sinemet CR is clearly indicated. Guidelines substituting Sinemet CR in place of levodopa/DCl are presented in Table 3, based on the product's monograph.

\section{CONClusions}

The use of Sinemet CR in de novo patients is perhaps the most promising advantage of this agent based on the theoretical ground that more stable levodopa levels may help prevent desensitization of striatal DA receptors and avoid or delay the appearance of therapeutic response fluctuations. If MAO-B inhibitors such as selegiline really delay the need for treatment with levodopa by their antioxidant-mediated protective effects on nigral cell survival, ${ }^{22}$ the combination of an MAO-B inhibitor and Sinemet CR may be the most powerful therapy for patients with PD in terms of long term stability of motor control.

\section{ACKNOWLEDGEMENTS}

The authors wish to acknowledge Mrs. Lyne Jean-Morrison for her expert secretarial assistance as well as Drs. Michèle Piotte and Maged Sadek for their professionalism as clinical monitors. 


\section{REFERENCES}

1. Fahn S. Fluctuations of disability in PD.: pathophysiology. In: Marsden CD, Fahn S, eds. Movements Disorders. Butterworths International Medical Reviews Neurology 2. London: Butterworth, 1982: 119-126.

2. Obeso JA, Grandas F, Vaamonde J, et al. Motor complications associated with chronic levodopa therapy in Parkinson's disease. Neurology 1989; 39 (Suppl 2): 11-19.

3. Cedarbaum JM. The promise and limitations of controlled-release oral levodopa administration. Clin Neuropharmacol 1989; 12: 147-166.

4. Yeh KC, August TF, Bush DF, et al. Pharmacokinetics and bioavailability of Sinemet CR: a summary of human studies. Neurology 1989; 39 (Suppl 2): 25-38.

5. Curzon G, Friedel J, Grier L, et al. Sustained release levodopa in Parkinsonism, Lancet 1973; 1: 781 .

6. Laitinen LV. Slowly absorbed L-dopa preparation in the treatment of parkinsonism. Act Neurol Scand 1973; 49: 331-338.

7. Poewe WH, Lees AJ, Stern GM. Treatment of motor fluctuation in Parkinson's disease with an oral sustained-release preparation of L-dopa: clinical and pharmacokinetic observations. Clin Neuropharmacol 1986; 9:430-439.

8. Cedarbaum JM, Breck L, Kutt H, et al. Controlled-release levodopa/carbidopa II. Sinemet CR4 treatment of response fluctuations in Parkinson's disease. Neurology 1987; 37: 1607-1612.

9. Duvoisin RC. New strategies in dopaminergic therapy of Parkinson's disease: the use of a controlled-release formulation. Neurology 1989; 39 (Suppl 2): 4-6.

10. LeWitt PA, Nelson MV, Berchou RC, et al. Controlled-release carbidopa/levodopa (Sinemet 50/200 CR4): clinical and pharmacokinetic studies. Neurology 1989; 39 (Suppl 2): 45-53.

11. Wilding IR, Davis SS, Melia CD, et al. Gastrointestinal transit of Sinemet CR in healthy volunteers. Neurology 1989; 39 (Suppl 2): $53-59$.
12. Aarli JA, Gilhus NE. Sinemet CR in the treatment of patients with Parkinson's disease already on long-term treatment with levodopa. Neurology 1989; 39 (Suppl 2): 82-85.

13. Bush DF, Liss CL, Morton A, et al. An open multicenter long-term treatment evaluation of Sinemet CR. Neurology 1989; 39 (Suppl 2): $101-105$.

14. Deleu D, Jacques $M$, Michotte $Y$, et al. Controlled-release carbidopa/levodopa $(C R)$ in parkinsonian patients with response fluctuations on standard levodopa treatment: clinical and pharmacokinetic observations. Neurology 1989; 39 (Suppl 2): 88-92.

15. Goetz CG, Tanner CM, Gilley DW, et al. Development and progression of motor fluctuations and side-effects in Parkinson's disease: comparison of Sinemet CR versus carbidopa/levodopa. Neurology 1989; 39 (Suppl 2): 63-67.

16. Rinne UK, Rinne JO. Treatment of early Parkinson's disease with controlled-release levodopa preparations. Neurology 1989: 39 (Suppl 2): 78-82.

17. Rodnitzky RL, Dickins QS, Dobson J. Long-term clinical efficacy of Sinemet CR in patients with Parkinson's disease. Neurology 1989; 39 (Suppl 2): 92-95

18. Rondot $\mathrm{P}$, Ziegler M, Aymard N, et al. Effect of controlled-release carbidopa/levodopa on motor performance in advance Parkinson's disease. Neurology 1989; 39 (Suppl 2): 74-78.

19. Ulm G, Gerdes U, Haagen K. Experiences with Sinemet $C R$ in the Paracelsus-Elenaklinik. Neurology 1989; 39 (Suppl 2): 85-88.

20. Feldman RG, Mosbach PA, Kelly MR, et al. Double-blind comparison of standard Sinemet and Sinemet CR in patients with mildto-moderate Parkinson's disease. Neurology 1989; 39 (Suppl 2): 96-10

21. Hutton JT, Morris JL, Bush DF, et al. Multicenter controlled study of Sinemet CR vs Sinemet (25/100) in advanced Parkinson 's disease. Neurology 1989; 39 (Suppl 2): 67-72.

22. Parkinson Study Group. Effect of Deprenyl on the progression of disability in early Parkinson's disease. New Eng J Med 1989; 321: 1364-1371. 